\title{
REFORMA DO ESTADO BRASILEIRO E A EXPANSÃO DA EDUCAÇÃO A DISTÂNCIA NO BRASIL (1996-2016)
}

\author{
REFORMA DEL ESTADO BRASILEÑO Y LA EXPANSIÓN DE LA EDUCACIÓN A \\ DISTANCIA EN BRASIL (1996-2016)
}

\author{
REFORM OF THE BRAZILIAN STATE AND THE EXPANSION OF DISTANCE \\ EDUCATION IN BRAZIL (1996-2016)
}

\author{
Stela Galbardi de RESENDE ${ }^{1}$ \\ Maria Luisa Furlan COSTA ${ }^{2}$
}

RESUMO: Este artigo tem como objetivo refletir sobre as políticas públicas para a Educação Superior a Distância no Brasil no atual contexto socioeconômico, com recorte temporal de 1996 a 2016. Utilizou-se como procedimento metodológico a pesquisa bibliográfica e documental com abordagem qualitativa. As transformações no cenário nacional, no que tange às exigências e interferências dos organismos internacionais na reforma do Estado brasileiro, refletem na expansão desta modalidade no ensino a partir da LDBEN (lei n $\left.{ }^{\circ} 9.394 / 96\right)$. Viu-se que o campo da Educação Superior no Brasil se transformou com aumento significativo na expansão e consequentemente ao acesso a esse nível de ensino, resultado da adoção de políticas direcionadas à utilização das Tecnologias de Informação e Comunicação, indispensável no processo de democratização da educação.

PALAVRAS-CHAVE: Políticas públicas. EaD. Reforma do Estado. Ensino superior.

RESUMEN: Este artículo tiene como objetivo reflexionar sobre las políticas públicas para la Educación Superior a Distancia en Brasil en el actual contexto socioeconómico, con recorte temporal de 1996 a 2016. Se utilizó como procedimiento metodológico la investigación bibliográfica y documental con abordaje cualitativo. Las transformaciones en el escenario nacional, en lo que se refiere a las exigencias e interferencias de los organismos internacionales en la reforma del Estado brasileño, reflejan en la expansión de esta modalidad en la enseñanza a partir de la LDBEN (ley $n^{\circ} 9.394$ /96). Se vio que el campo de la Educación Superior en Brasil se transformó con un aumento significativo en la expansión $y$ consecuentemente al acceso a ese nivel de enseñanza, resultado de la adopción de políticas dirigidas a la utilización de las Tecnologías de Información y Comunicación, indispensable en el proceso de democratización de la educación.

PALABRAS CLAVE: Política pública. Educación a distancia. Reforma del Estado Educación más alta.

\footnotetext{
${ }^{1}$ Universidade Estadual de Maringá (UEM), Maringá - PR - Brasil. Mestrado em Educação PPE/UEM. ORCID: <https://orcid.org/0000-0001-5119-6603>.E-mail: stela.galbardi@gmail.com

${ }^{2}$ Universidade Estadual de Maringá (UEM), Maringá - PR - Brasil. Professora do Departamento de Fundamentos da Educação, Maringá, PR. ORCID: <http://orcid.org/0000-0002-7838-0459>. E-mail: luisafurlancosta@gmail.com
} 
ABSTRACT: This article aims to reflect on the public policies for Distance Higher Education in Brazil in the current socioeconomic context, with a temporal cut from 1996 to 2016. The methodological procedure was the bibliographical and documentary research with a qualitative approach. The transformations in the national scenario, regarding the demands and interferences of the international organisms in the reform of the Brazilian State, reflect in the expansion of this modality in the education from the LDBEN (law 9.394 / 96). It was seen that the field of Higher Education in Brazil has transformed with a significant increase in the expansion and consequently the access to this level of education, result of the adoption of policies directed to the use of Information and Communication Technologies, indispensable in the process of democratization of education.

KEYWORDS: Public policy. Distance education. Reform of the State. Higher education.

\section{Introdução}

No que tange a reforma do estado brasileiro e a expansão da EaD no Brasil, o recorte temporal se inicia em 1996 devido a promulgação da Lei de Diretrizes e Bases na Educação Nacional no 9.394 que em seu art. 80 institui a Educação a Distância e, se encerra, em 2016, quando foram elaboradas as novas Diretrizes da EaD (BRASIL, 2016).

Ao discutir a expansão da $\mathrm{EaD}$ no Brasil faz-se necessário refletir sobre a democratização do acesso ao ensino superior que envolve uma compreensão do que de fato tem se efetivado, por tratar do aumento do número de pessoas que iniciam, mas não necessariamente finalizam os cursos superiores.

O Plano Nacional da Educação (PNE) 2001-2010 estabeleceu que ao final desse decênio a meta era alcançar 30\% da taxa líquida de matrículas de jovens entre 18 e 24 anos no ensino superior. Entretanto, dados do Instituto Brasileiro de Geografia e Estatística/ Pesquisa Nacional por Amostra de Domicílios (IBGE/Pnad) de 2014 demonstram que o percentual de alunos matriculados nessa faixa etária era de apenas 16,5\% da população (ARRUDA, 2015).

Esses dados demonstram, portanto, um percentual bem distante do objetivo anterior e da meta do novo Plano Nacional da Educação 2014-2024 que é alcançar o percentual de 33\% da taxa líquida e 50\% da taxa bruta de matrículas nessa faixa etária, sendo que essa expansão seria da ordem de $40 \%$ para o segmento público. Esse percentual de matrículas existentes significaria uma ampliação de quatro milhões de vagas, sendo cerca de 1,6 milhão apenas no segmento público (ARRUDA, 2015).

Para fins de comparação das possibilidades de expansão, de acordo com dados do IBGE/Pnad (2016) e Censo elaborado pela Diretoria de Estatísticas Educacionais (DEED) do 
Inep (2016), enquanto as matrículas na Educação Superior presencial aumentaram de três milhões em 2001 para pouco mais de que seis milhões e meio em 2016, as matrículas no ensino superior na modalidade a distância saltaram de pouco mais de três mil em 2001 para cerca de 1,5 milhão em 2016, sendo que quase 2 milhões de matrículas foram ofertadas por instituições públicas de ensino superior (BRASIL, 2016b) e as demais por instituições privadas. Como afirma Dourado (2002):

As alterações provocadas pelas políticas educacionais no Brasil não podem ser compreendidas sem o entendimento das contingências históricas e econômicas que balizam o cenário atual das transformações societárias do mundo atual (DOURADO, 2002, p. 245).

Nessa expansão importa identificar e verificar em que medida as expectativas são de fato atendidas e qual o contexto histórico, econômico e social em que essas transformações foram engendradas.

\section{A influência neoliberal na expansão do ensino superior}

Para compreender as políticas públicas que nortearam a expansão do ensino superior, especialmente na modalidade a distância, investigou-se a respeito da influência do ideário neoliberal $^{3}$ nas políticas educacionais no Brasil, que enfatizaram a qualidade, a adequação às demandas do mercado, a competitividade e a contínua qualificação profissional, traços inerentes do neoliberalismo:

Consubstanciando essa lógica, propõe, ainda, o enxugamento da máquina estatal e privatização de bens e serviços em que a reforma do Estado é entendida como superação de "visões do passado de um Estado assistencialista e paternalista" por meio da transferência da produção de bens e serviços "à sociedade, à iniciativa privada" (DOURADO, 2002, p. 236).

O ideário neoliberal preceitua que o mercado é que deve gerir as atividades socioeconômicas, reduzindo o "poder" do Estado nas questões econômicas e sociais. Esse "modelo" de economia busca a sua hegemonia global, isto é, objetiva a manutenção da posição

${ }^{3}$ Nessa ótica, o neoliberalismo designa uma tendência hegemônica contemporânea [...] “A perspectiva neoliberal situa-se, como uma reformulação do padrão de gestão do desenvolvimento do capitalismo, presente na concepção de Estado liberal intervencionista Keynesiana, vigente na vertente denominada Welfare State, ou Estado de BemEstar Social, caracterizado, entre outros aspectos, pela implementação da esfera pública por meio do incremento de políticas sociais, postulando a garantia de padrões mínimos de vida visando a manter o estímulo ao desenvolvimento e a consolidação das economias de mercado; nesse caso, trata-se, portanto, do fortalecimento do papel do Estado, por intermédio da adoção de uma feição intervencionista na economia” (DOURADO, 2002, p. 247). 
social da classe dominante, como também almeja mais "poder" - o lucro (GENTILI, 2007). Sobre isso Mendonça também discorre:

O neoliberalismo, influenciado pelo Banco Mundial e pelos organismos internacionais, interveio na elaboração das políticas públicas de grande parte dos países na década de 1990, sendo implantado de forma diferente em cada país, de acordo com a estrutura socioeconômica e política ali vigente. No Brasil, o neoliberalismo foi introduzido por meio do Plano Diretor da Reforma do Aparelho do Estado no período em que Fernando Henrique Cardoso estava na Presidência da República (1995 - 2002), cujas diretrizes inspiraram um conjunto de reformas investido em sua gestão e que permanecem até os dias atuais (MENDONÇA, 2016, p. 101-102).

De acordo com o diagnóstico apresentado no PNE (2010) o Estado pondera sobre a importância e a necessidade de consolidar a Educação de forma geral e especificamente no caso da EaD como modalidade assistencial da política pública da educação, no processo de universalização e democratização do ensino, especialmente no Brasil, onde os déficits educativos e as desigualdades regionais são tão elevados. Os desafios educacionais existentes podem ter, na Educação a Distância, um meio auxiliar de indiscutível eficácia. Além do mais, os programas educativos podem desempenhar um papel inestimável no desenvolvimento cultural da população em geral (BRASIL, PNE/2010).

Sobre isso Arruda diz:

O PNE 2001-2010 refletiu duas abordagens distintas e complementares acerca da $\mathrm{EaD}$, de um lado um olhar mercantil, com alusões indiretas à ampliação da oferta e à redução de custos no desenvolvimento de cursos nesse formato. A $\mathrm{EaD}$, sob essa perspectiva do PNE 2001-2010, parece ser a resposta para os males que acometeram a educação brasileira ao longo dos últimos séculos. O outro olhar é de caráter instrumental e técnico. Tem-se a impressão de que, em complemento à visão anteriormente discutida, a presença quantitativa de equipamentos (computadores, televisores, etc.) por si só garantiria a melhoria da educação e a possibilidade da oferta de cursos à distância (ARRUDA, 2015, p. 325).

Nesse sentido, percebe-se que o Estado aposta na EaD como um mecanismo eficaz para reduzir os problemas constituintes da crise na/da educação do país, acumulados ao longo da implementação de programas educacionais que não sanaram os problemas pertinentes aos déficits educacionais e às disparidades regionais. Porém, existem muitos desafios para a superação das desigualdades educacionais, como aponta Edith Litwin:

É preciso, portanto, que no futuro, a Educação a Distância seja pensada como parte das políticas implantadas para reduzir desigualdades, e não como instrumento para aprofundá-las. Esse é o seu desafio (LITWIN, 2001, p. 22). 
O desafio parece continuar o mesmo, uma vez que o neoliberalismo fundamenta-se na assertiva perante o fato de que a Educação Superior afigura-se mais como um bem de consumo regulado pelo mercado:

[...] a grande operação estratégica do neoliberalismo consiste em transferir a educação da esfera da política para a esfera do mercado, questionando assim seu caráter de direito e reduzindo-a a sua condição de propriedade. É neste quadro que se reconceitualiza a noção de cidadania, através de uma revalorização da ação do indivíduo enquanto proprietário, enquanto indivíduo que luta para conquistar (comprar) propriedades-mercadorias diversa índole [sic], sendo a educação uma delas. O modelo de homem neoliberal é o cidadão privatizado, o entrepreneur, o consumidor (GENTILI, 1996, p. 20-21).

Sobre a visão da educação como bem de consumo, percebe-se que a legislação brasileira tem mudado no decorrer dos anos, pois a lei específica que tratava da desregulamentação dos serviços educacionais foi publicada pelo Decreto $\mathrm{n}^{\circ} 2.306$, de 19 de agosto de 1997. Este foi revogado pelo Decreto $n^{\circ} 3.860$, de 2001; revogado também pelo Decreto $n^{\circ} 5.773$, de 2006 e por último revogado pelo Decreto $n^{\circ} 9.235$, de 2017 que está em vigor no momento. Este dispõe sobre o exercício das funções de regulação, supervisão e avaliação das instituições de Educação Superior e dos cursos superiores de graduação e de pós-graduação no sistema federal de ensino. Todo o histórico de alterações e mudanças na legislação apontaram para a consolidação das ações neoliberais para a Educação Superior no Brasil.

Então, para uma melhor compreensão da influência do neoliberalismo nas políticas de Educação a Distância, é preciso desvendar o projeto que o fundamentou. O cenário mundial de instabilidade econômica pós-Grande Depressão, crise 1929, culminou na $2^{\text {a }}$ guerra mundial e é neste contexto que surge a nova ideologia no início século $\mathrm{XX}-\mathrm{o}$ Neoliberalismo - com Ludwig von Mises (1881-1973) e Friedrich von Hayek (1899-1992):

[...] o neoliberalismo, [...], é a ideologia do capitalismo na era de máxima financeirização da riqueza, a era da riqueza mais líquida, a era do capital volátil - e um ataque às formas de regulação econômica do século XX, como o socialismo, o keynesianismo, o Estado de bem-estar, o terceiro mundismo e o desenvolvimento latino-americano (MORAES, 2001, p. 4).

Esta nova ideologia doutrinária proposta por estes e outros economistas franceses, alemães e norte-americanos, na primeira metade do século XX, se volta para a adaptação dos princípios do liberalismo clássico às exigências de um Estado regulador e assistencialista, que deveria controlar parcialmente o funcionamento do mercado. Conforme salienta Morais: 
O liberalismo clássico havia assestado suas baterias contra o Estado mercantilista e as corporações. Os neoliberais procuraram desde logo construir um paralelo com aquela situação, para justificar seu combate e apresentá-lo como a continuação de uma respeitável campanha antiabsolutista. Segundo eles, os inimigos vestiam agora outros trajes, mas revelavam as mesmas taras e perversões. Um desses inimigos era o conjunto institucional composto pelo Estado de bem-estar social, pela planificação e pela intervenção estatal na economia, tudo isso identificado com a doutrina keynesiana (MORAES, 2001, p. 13).

Esses princípios ganharam forças após a grande crise do capital de 1973, com o crescimento da concorrência comercial e com a necessidade de sustentar a suposta supremacia que o capitalismo demonstrava conquistar sobre o sistema socialista. Sobre esse processo Pablo Gentili afirma ser um ambicioso projeto de reforma ideológica:

Com efeito, o neoliberalismo expressa a dupla dinâmica que caracteriza todo processo de construção de hegemonia. Por um lado, trata-se de uma alternativa de poder extremamente vigorosa constituída por uma série de estratégias políticas, econômicas e jurídicas orientadas para encontrar uma saída dominante para a crise capitalista que se inicia ao final dos anos 60 e que se manifesta claramente já nos anos 70 . Por outro lado, ela expressa e sintetiza um ambicioso projeto de reforma ideológica de nossas sociedades a construção e a difusão de um novo senso comum que fornece coerência, sentido e uma pretensa legitimidade às propostas de reforma impulsionadas pelo bloco dominante (GENTILI, 1996, p. 9).

No Brasil, em decorrência do Regime Militar que aconteceu entre 1964 a 1985, esse processo de reformas e adaptações se iniciou um pouco mais tarde. A reformulação das formas de gestar a educação pública brasileira começou no final da década de 1980, com a promulgação da nova Constituição Federal, das Constituições Estaduais e das Leis Orgânicas municipais.

Ao investigar o contexto histórico das políticas públicas para a Educação Superior no Brasil e em outros lugares, Carvalho afirma que:

Nos anos 90, todo o espectro de políticas sociais e econômicas esteve sob a influência da chamada Agenda Neoliberal. O conjunto de propostas assumiu um caráter abrangente, com implicações para além das fronteiras nacionais, $o$ que confere especificidade à década (CARVALHO, 2007, p. 85).

Na perspectiva de Luiz Carlos Bresser Pereira, ideólogo da Reforma do Estado, no mandato do Presidente da República Fernando Henrique Cardoso, a reforma do Estado pode ser conceituada como um processo de "[...] criação ou de transformação de instituições de forma a aumentar a governança e a governabilidade" (BRESSER-PEREIRA, 1998, p. 61). Para o autor, a reforma seria uma maneira de definir o papel do Estado, consentir para o setor privado e o setor público não-estatal grande parte das atividades que eram de responsabilidade do 
Estado. A política neoliberalista assinala a necessidade das reformas educacionais como uma forma de responder às crises sociais:

A Reforma na década de 1990 foi influenciada pelo advento do modelo neoliberal nos âmbitos político e econômico. Apesar do fortalecimento das forças sociais progressistas no processo de transição democrática, o modelo neoliberal impôs-se pela insatisfação generalizada frente à continuidade dos sérios problemas econômicos e sociais legados dos governos militares. A Reforma educacional no Brasil iniciou-se na segunda metade da década de 1990 com o intuito de consolidar uma nova forma de gestão da educação e da escola e, ao mesmo tempo, reverter o exíguo atendimento do ensino fundamental e médio bem como os altos índices de fracasso e evasão escolar (KRAWCZYK; VIEIRA, 2010, p. 10).

Ao final da Segunda Guerra Mundial, em 1944, aconteceu uma conferência com 730 delegados das 44 nações aliadas que se reuniram na cidade de Bretton Woods, no estado de New Hampshire para estabelecer as bases do funcionamento capitalista no pós-guerra nos Estados Unidos da América (EUA). Esse evento ficou conhecido como conferência de Bretton Woods que, antes mesmo do fim da guerra, estavam confiantes que a vitória estabeleceria os EUA como império dominante. A partir desse momento foram criados os Organismos Internacionais, entre eles o Fundo Monetário Internacional (FMI) e o Banco Mundial (BM), com o objetivo formal de financiar a reconstrução das economias destruídas pela guerra e garantir a estabilidade monetária (OLIVEIRA, 2010).

Essas mesmas instituições de Bretton Woods se organizaram em 1989, para iniciar sua intervenção nos países latino-americanos, com o discurso da necessidade de superar a crise da dívida externa. Estas reuniões ficaram conhecidas como o Consenso de Washington (MOREIRA; LARA, 2012).

Em 1989, na América Latina, em vista da crise da dívida externa e em atendimento ao Consenso de Washington, foram elaboradas políticas de ajustes, ou seja, estratégias econômicas com uma rigorosa disciplina fiscal, privatização, redução dos gastos públicos, reformas (tributárias, previdência etc.), liberalização comercial, desregulamentação da economia e flexibilização das relações trabalhistas, dentre outras (MOREIRA; LARA, 2012, p. 65).

Relativamente à educação, a UNESCO realizou a conferência mundial de educação em Jomtien, na Tailândia em 1990, que resultou no acordo da Educação para Todos envolvendo diversos países. Essa conferência apontou a necessidade de a educação formar um homem 
flexível e empreendedor, enfatizando-a como um caminho para contribuir com o desenvolvimento econômico e social desses países (GAJARDO, 2000).

Como resultado desse acordo internacional, a Reforma educacional brasileira ocorrida na década de 1990 aconteceu concomitantemente às mudanças no âmbito econômico e político que radicalizaram a implantação de medidas neoliberais, iniciada na ditadura militar, medidas essas que institucionalizaram o Estado mínimo. Como afirmam Krawczyk e Vieira:

A reconfiguração do papel do Estado com a institucionalização do Estado mínimo resultou, no caso da educação, em um processo de centralização descentralização pelo qual não só mudou a histórica relação federativa no país como também atribuiu um novo papel ao Estado, à iniciativa privada e à pessoa física na educação. A descentralização era uma característica constituinte da educação formal no Brasil, porém, com a Reforma Educacional, sofreu uma forte regulamentação que afetou a distribuição de responsabilidades e atribuições entre os diferentes níveis de governo - estados e municípios - e a redistribuição de recursos em cada estado da federação (KRAWCZYK; VIEIRA, 2010, p. 12).

Sobre essa descentralização, Gajardo salienta que:

No Brasil, por exemplo, a educação sempre foi uma responsabilidade compartilhada entre os governos federal, estaduais e municipais, com a coexistência de duas redes de ensino público: a estadual e a municipal. Embora ao governo federal caiba administrar a Educação Superior, na prática a distribuição de competências entre os distintos níveis sofre forte influência de um modelo de alocação de recursos em que o governo da União utiliza múltiplos canais e mantém a responsabilidade pela execução de grandes projetos e programas em nível nacional (GAJARDO, 2000, p. 16).

Observa-se que as reformas ocorridas após o Consenso de Washington (1989) e a Conferência de Jomtien (1990) objetivaram atender ao ideário neoliberal que, por sua vez, busca desregulamentar, reduzir ao máximo, a participação do Estado na economia e nos mercados, isto é, descentralizar. Um Estado desregulamentado aponta para a mercantilização dos serviços sociais com as ideias de privatização e terceirização na execução de serviços estatais. Todas essas mudanças, reformas e adaptações fizeram parte da reestruturação do capitalismo no âmbito universal demandando ajustes estruturais nas políticas econômicas, e por sua vez, nas políticas públicas em geral que inclui as educacionais (LARA; DIAS, 2008). Sobre isso, Dourado afirma:

Tais políticas têm resultado em um intenso processo de massificação e privatização da Educação Superior no Brasil, caracterizado pela precarização e privatização da agenda científica, negligenciando o papel social da Educação Superior como espaço de investigação, discussão e difusão de projetos e 
modelos de organização da vida social, tendo por norte a garantia dos direitos sociais (DOURADO, 2002, p. 246).

Nesse sentido, ao pensar no acesso a uma educação de qualidade, de caráter marcadamente emancipatória, não só daquilo que é básico e necessário para a integração social, mas que também envolve a formação ampla e cidadã, há que se falar em democratização da educação.

\section{As políticas de EaD: estratégia para democratização do ensino superior}

Segundo Faria (2006), a democratização do ensino é entendida como a possibilidade de universalizar e socializar o acesso à educação, para que o ensino possa atingir a todos. Assim, atender os educandos dispersos geograficamente, encurtando distâncias, só é possível mediante o uso das tecnologias que permitem à Educação a Distância dar um novo sentido à função social do ensino com igualdade de oportunidades. Para Mendonça:

No entanto, não podemos conceber a Educação a Distância somente pela lógica neoliberal, ou seja, como uma mercadoria que é vendida para satisfazer aos anseios da formação de mão de obra para o mercado de trabalho. A EaD foi implementada como uma estratégia para a democratização do acesso à educação pública de qualidade, mas idealizá-la de forma diferente não condiz com as lutas e a trajetória histórica que essa modalidade de ensino tem enfrentado para que de fato tenhamos uma educação pública de qualidade para todos (MENDONÇA, 2016, p. 103).

A EaD é uma modalidade educacional que usa como ferramentas as tecnologias de informação e comunicação (TIC), que se transformam em materiais (recursos) didáticos, desde que aplicadas intencionalmente ao processo educativo, promovendo a construção e a socialização do conhecimento (BOLSONI, 2015). Sobre isso Loing considera que:

É inicialmente necessário distinguir dois caminhos, complementares, mas diferentes: o de ensinar com as tecnologias e o de aprender com as tecnologias [...] Há anos que se aprende com o apoio de máquinas, mas ainda não se sabe bem como ensinar com elas (LOING, 1998, p. 41).

A EaD vai além da utilização das tecnologias em sala de aula, pois envolve uma visão mais ampla que requer a interatividade, a relação entre professor e aluno, apresentando como ganho a aquisição do conhecimento (NISKIER, 1999). 
Ao analisar os Referenciais de Qualidade para a $\mathrm{EaD}^{4}$, pode-se entender que essa modalidade, antes de mais nada, é educação e que independentemente da modalidade de ensino, o termo "a distância" é apenas o modo de ensinar. Então, tanto o Decreto no 5.622/05 (BRASIL, 2005) e o recente Decreto $\mathrm{n}^{\circ}$ 9.057/17 (BRASIL, 2017), bem como os Referenciais de Qualidade vieram contribuir para normatizar o que já apontava a LDBEN no 9.394/96 (BRASIL, 1996), sendo possível afirmar que a EaD se apresenta como uma possibilidade de ensino importante no que se refere à democratização da educação e à minimização de muitas desigualdades, e especificamente, a da falta de qualificação dos professores do país. ${ }^{5}$

A Educação a Distância surge, então, para acompanhar essa demanda, pois caracterizase como uma modalidade de ensino que transmite o conhecimento sem a presença física de professores e alunos, com a interação possibilitada pelo uso das tecnologias de informação e comunicação. Nessa modalidade, o ensino superior pode chegar a lugares nos quais o acesso presencial é difícil, fato que, em tese, democratiza e interioriza a oferta desse nível de ensino superior no Brasil (COSTA; LOZANO, 2013).

De acordo com Oliveira (2014), a modalidade não é nova, embora não haja um consenso sobre quando ela começou e tão pouco registros significativos das experiências realizadas em EaD no Brasil. Nos livros ou manuais de História de Educação utiliza-se como marco as experiências de Edgard Roquette-Pinto nas décadas de 1920 e 1930, com a criação de duas rádios e a proposta do rádio educativo. Sobre isso Oliveira afirma que:

Ao defender a necessidade de se oferecer educação ao povo brasileiro, Roquette-Pinto propõe o rádio educativo, pois mediante esse instrumento se promoveria a integração da nação, se construiria a identidade nacional e se possibilitaria a educação dos que não tinham escola (OLIVEIRA, 2014, p. 25).

Neste mesmo intuito, um pouco mais tarde, houve a criação de duas instituições com o objetivo específico de promover a EaD: o Instituto Rádio Monitor (1939), ligado ao ramo da eletrônica; e o Instituto Universal Brasileiro (1941), que oferecia formação profissional de nível

\footnotetext{
${ }^{4}$ Os Referenciais de Qualidade para a EaD foram elaborados pelo MEC, no ano de 2007. Esse documento é fruto de sucessivas discussões entre especialistas, universidades e sociedade. O primeiro texto oficial foi divulgado pelo MEC em 2003, o qual disponibiliza esses Referenciais como indicadores de qualidade para os cursos de EaD (BRASIL, 2007 apud OLIVEIRA, 2014).

5 Sobre a importância da EaD principalmente em locais que apresentam baixa oferta de cursos de formação superior: A Educação a Distância $(\mathrm{EaD})$ é uma modalidade de ensino empregada no intuito de ampliar as possibilidades de acesso ao conhecimento. Sua combinação ao avanço tecnológico e da comunicação vem para equacionar a diferença entre a baixa oferta de vagas na rede de ensino superior e a demanda por inclusão social a uma parcela maior da população, promovendo, assim, a democratização do acesso ao conhecimento (FILATRO, 2007). Além da democratização, a educação a distância apresenta notáveis vantagens sob o ponto de vista da eficiência e da qualidade, mesmo quando há grande volume de alunos ou se observa, em prazos curtos, o crescimento vertiginoso da demanda por matriculas" (NUNES, 2009).
} 
elementar e médio. Esse último oferecia cursos técnicos profissionalizantes por correspondência (OLIVEIRA, 2014).

Este era apenas o início da longa trajetória da EaD no Brasil. A partir da década de 1950 até meados do ano de 1998 foram muitas iniciativas, propostas e projetos de educação por meio do uso de rádio e televisão, dentre elas destacaram-se, na década de 1980, algumas iniciativas concretas de ensino superior desencadeadas pelo programa de ensino a distância da Universidade de Brasília, visando a oferecer cursos de extensão universitária. Ressalta-se que essas tentativas foram fundamentais para o reconhecimento oficial da $\mathrm{EaD}$, abrangida na Lei de Diretrizes e Bases da Educação Nacional, promulgada em 20 de dezembro de 1996 (OLIVEIRA, 2014).

Sobre esta trajetória, Costa afirma que:

A retomada histórica da criação e desenvolvimento da Educação a Distância no Brasil mostra um crescimento considerável nos últimos anos, com indícios de que em um futuro próximo o espaço a ser ocupado pelos cursos ofertados em uma modalidade distinta do ensino presencial será ainda maior. A inserção das novas tecnologias de informação e comunicação na educação abre inúmeras possibilidades para que, cada vez mais, os cursos a distância possam cumprir sua função social no processo de democratização do ensino público e de qualidade (COSTA, 2014, p. 18).

Nesse sentido, pode-se afirmar que a Educação a Distância possibilita, além da democratização do conhecimento, uma oportunidade ímpar para a formação de professores, formação continuada e uma melhor qualificação profissional, inclusive no que diz respeito à utilização de suas ferramentas.

Nas mesas internacionais de discussão ${ }^{6}$ com relação à Educação Superior evidenciamse muitas problemáticas que afligem a educação, entre elas a preocupação demasiada com a expansão, a interiorização e a ampliação da educação em nível superior; os objetivos da Educação Superior e sua função no século XXI; qual o papel e o lugar das universidades na era virtual. Nos oito anos do Governo Fernando Henrique Cardoso houve uma expansão acelerada das matrículas, pois estabeleceram como meta que as instituições particulares matriculassem mais de 70\% do total de estudantes nesse período (DOURADO; CATANI; OLIVEIRA, 2003, p. 24).

No que diz respeito a Educação a Distância Mendonça salienta que:

${ }^{6}$ Nas mesas de discussão dos Órgãos, Organismos e Agências Internacionais. 
No final do século XX e início do século XXI, houve uma acentuada demanda de ingresso em curso de nível superior devido ao disposto na LDBEN, Lei ${ }^{\circ}$ 9.394/96, que prevê a formação em nível superior de todos os profissionais da educação, o que causou a expansão da $\mathrm{EaD}$ e a acentuação do preconceito criado em torno deste nível de ensino (MENDONÇA, 2016, p. 40).

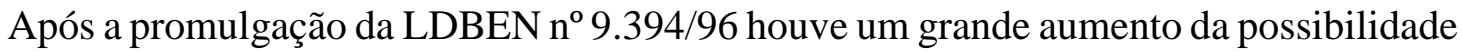
de acesso ao ensino superior, tanto presencial como a distância. Os dados do Censo 2015 (atualizado em outubro de 2016) mostram que houve a abertura de 1.442 instituições de ensino superior (crescimento de 156\%) até o ano de 2015. Aumento esse que oportunizou a abertura de mais 26.857 cursos (crescimento de 404\%) possibilitando 6.158 .768 matrículas a mais no ensino superior no decorrer desses 19 anos. $^{7}$

Na modalidade a distância, quanto ao ingresso no ensino superior o crescimento passou de "zero" no ano da promulgação da Lei no 9.394/96 para 212.246 ingressantes em 2006. O Censo revela que a quantidade de matrícula em 2015 foi de 1.393.752, sendo que deste montante 1.265.359 foram matriculados em instituições de ensino superior (IES) privadas. Mas quando comparados os últimos 10 anos de registro do Censo (2005-2015), o aumento no ingresso de alunos na Educação Superior na modalidade a distância passou de 127.014 para 1.393.752 matrículas, que corresponde a um crescimento de 997\% (BRASIL, 2015b).

O crescimento e a expansão da Educação a Distância foram possíveis somente porque houve a implementação de alguns programas do governo, em níveis federal, estadual e municipal, visando ao aumento da oferta de cursos e ao acesso da população à educação em nível superior. Nesse contexto, cabe destacar a criação do Sistema Universidade Aberta do Brasil, por meio do Decreto $\mathrm{n}^{\circ} 5.800$ de 8 de junho de 2006 (MENDONÇA, 2016, p. 45).

Diante do processo paulatino da resistência e do questionamento das bases que sustentam o modelo de universidade de pesquisa, o processo de mercantilização do ensino superior e a consequente institucionalização dele no mercado têm gerado muitas discussões (CALDERÓN, 2000). No que diz respeito a EaD, essas discussões se intensificam ainda mais. De acordo com Demo (1995), partindo-se de uma abordagem dialética faz-se necessário questionar a "tese", isto é, indagar a intervenção estatal na garantia da Educação Superior como direito social, que é negada pela sua antítese, portanto, o discurso neoliberal, que incentiva o afastamento do Estado, o que acabaria por constituir em termos práticos no:

[...] discurso neoliberal, que prega a não-intervenção estatal, geraria, como síntese, a negação da negação, que acenaria para a prevalência do novo, que,

${ }^{7}$ Dados levantados pela própria autora tendo como referência os Censos 1996-2015 (BRASIL, Inep, 2015) 
neste caso, seria o modelo de universidade recomendada pela Unesco: as instituições públicas não estatais, baseadas nas parcerias público-privadas. Instituições universitárias que preservam seu caráter público, mas gerenciadas pela iniciativa privada. Instituições sem fins lucrativos, preocupadas com a qualidade e responsabilidade da Educação Superior (CALDERÓN; PEDRO; VARGAS, 2011, p. 1194).

Nos anos 1990, a reforma foi vista como a própria política educacional governamental, materializou-se por meio de legislação, financiamento de programas governamentais e uma série de ações não governamentais que envolveram participações em fóruns, exploração midiática de iniciativas educacionais, campanhas de divulgação das propostas governamentais em publicações oficiais, entre outras iniciativas marcadas pela orientação de intelectuais juntamente com organismos nacionais e internacionais (SHIROMA; MORAES; EVANGELISTA, 2011).

$\mathrm{O}$ final do século XX marca uma ascensão de uma esquerda Latino-americana (Argentina, Equador, Colômbia, Uruguai, Venezuela, México) em resposta a esse movimento neoliberal. O início do século XXI trouxe um novo momento político na América Latina com

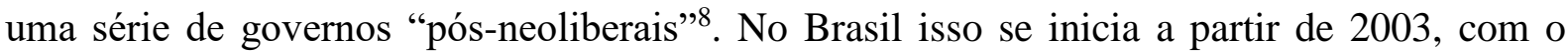
Governo Luiz Inácio Lula da Silva (2003-2010).

No livro organizado pelo sociólogo e cientista político Emir Sader (2013) sobre os 10 anos de governos pós-neoliberais no Brasil, ele conceitua:

Os traços que esses governos têm em comum, que permite agrupá-los na mesma categoria (pós-neoliberalistas), são: a) priorizam as políticas sociais e não o ajuste fiscal; b) priorizam os processos de integração regional e os intercâmbios Sul-Sul e não os tratados de livre-comércio com os Estados Unidos; c) priorizam o papel do Estado como indutor do crescimento econômico e da distribuição de renda, em vez do Estado mínimo e da centralidade do mercado (SADER, 2013, p. 138).

No que diz respeito ao cenário de expansão da Educação Superior especificamente no Brasil, faz-se importante ressaltar os governos seguintes ao de FHC, liderados pelo presidente Lula (2003-2010):

Por ora, é importante ressaltar que o plano de governo apresentado em 2002 por Lula, como proposta para a Educação Superior, indicava a — ampliação

${ }^{8}$ Os governos do Lula e da Dilma podem ser caracterizados como pós-neoliberais, pelos elementos centrais de ruptura com o modelo neoliberal - de Collor, Itamar e FHC - e pelos elementos que têm em comum com outros governos da região, como os Kirchners na Argentina, da Frente Ampla no Uruguai, de Hugo Chávez na Venezuela, de Evo Morales na Bolívia e de Rafael Correa no Equador. Esses governos representam uma reação antineoliberal no marco das grandes recessões que abalaram o continente, nas últimas décadas do século passado (SADER, 2013). 
significativa das vagas nas universidades públicas e a reformulação do sistema de crédito educativo vigente como instrumento para sanar, ainda que parcialmente, as questões levantadas, cujas fontes revelaram um acesso mínimo por parte de jovens pobres ao ensino superior público (BERTOLLETI, 2017, p. 115).

E quanto à Educação Superior a distância desse período, as políticas adotadas no Governo Lula possibilitaram a ampliação e democratização:

A análise das políticas adotadas pelo governo Lula indica que este privilegiou algumas questões da agenda da Educação Superior, como a ampliação e democratização de acesso, inclusive procurando o viés da equidade, ao contemplar populações historicamente não atendidas, quer por razões econômicas, quer, aliada a estas, raciais. Outra questão que mereceu destaque entre as políticas implementadas é a representada pelo par qualidade/massificação, uma vez que houve um razoável aperfeiçoamento dos instrumentos de avaliação, como garantidores da qualidade do sistema, ao lado de um grande incremento da Educação a Distância, com enfoque francamente massificador (AGUIAR, 2016, p. 124).

No que diz respeito às políticas educacionais e o projeto de reforma universitária defendido nos dois mandatos do Governo Lula, mesmo abrangendo a ampliação do acesso por meio de diversos programas governamentais (UAB, FIES, ProUni, REUNI), o ideário pedagógico do capital industrial (privatizações, mercantilização do ensino superior, entre outros) também ganha força. Sobre isso Antunes afirma:

De Obama a Sarkozy, do Fundo Monetário Internacional (FMI) ao Grupo dos 20 (G20) todos saudaram Luiz Inácio Lula da Silva, presidente do Brasil, na reunião realizada em Londres, em abril de 2009, como político da integração e da conciliação. Lula consolidou sua presença no bloco dos países emergentes, os chamados BRICs (Brasil, Rússia, Índia e China), e fortaleceu também sua posição de tertius na liderança latino-americana, alternativa entre Chávez e Morales (e, em menor medida Correa), de um lado, e Uribe e Calderón, de outro; seu campo é mais próximo da moderação de Bechelet e Vázquez (ANTUNES, 2011, p. 135).

Assim, pode-se afirmar que nos anos 2003 a 2010 temos no Brasil a presença de um governo conciliatório:

Das medidas citadas, ProUni e REUNI estão inseridos no quadro das políticas públicas relacionadas à "democratização" do acesso à educação superior. Com o ProUni, o governo federal vem salvando as instituições privadas por meio da compra de suas vagas ociosas e com o REUNI, vem conseguindo expandir o acesso ao ensino superior público a baixo custo (NOMERIANO; MOURA; DAVANÇO, 2012, p. 6) 
Essas políticas conciliatórias permitiram o crescimento do setor privado, mas também houve investimentos no setor público. $\mathrm{Na}$ tentativa de atender os empresários, os agentes em disputa, e ao mesmo tempo uma classe social mais baixa passa a ter oportunidade de ingresso no ensino superior; por isso o período do governo Lula foi visto como um governo de políticas de oportunidades de democratização. Sobre isso trataremos mais profundamente na última seção.

Com a Reforma Estatal brasileira, as políticas sociais e, principalmente as educacionais, passam a atender as diretrizes sugeridas pelos organismos internacionais como Banco Mundial (BM) e pelo Fundo Monetário Internacional (FMI).

\section{Considerações finais}

Tendo como suporte as reflexões sobre a Reforma do Estado Brasileiro e as Políticas Públicas para a Educação Superior a Distância no Brasil, foi possível compreender as transformações no cenário nacional e a partir da década de 90 , no que se relaciona às exigências e interferências dos organismos internacionais bem como à expansão desta modalidade após a reforma do Estado brasileiro.

Após a década de 1970, a grande crise nos Estados capitalistas redefiniu a forma de atuação do Estado-nação em um novo contexto com o neoliberalismo; a reestruturação produtiva juntamente com a globalização e a financeirização da economia trouxeram novas instâncias e organizações que influenciam, de forma crescente, as políticas internas. Nos anos 1990 esse Estado passou a ser recomposto nesse novo movimento neoliberal. Em uma sociedade capitalista as relações sociais são pautadas na desigualdade (luta de classes), produzindo, assim, suas contradições.

No Brasil, a reforma educacional do Estado ganha significação em 1996 quando foi promulgada, mesmo que tardiamente, a Lei das Diretrizes e Bases da Educação Nacional. Em seu artigo 80, ao instituir a EaD, o campo da educação superior no Brasil se transformou com aumento significativo na expansão e consequentemente ao acesso a esse nível de ensino, resultado da adoção de políticas direcionadas à utilização das Tecnologias de Informação e Comunicação, indispensável no processo de democratização da educação. Desde a publicação da LDB, um longo caminho foi percorrido até a recente publicação da resolução $\mathrm{n}^{\circ} 1 / 2016$, que caracteriza essa modalidade de ensino. Vê-se então, que o campo da Educação Superior no Brasil se transformou com aumento significativo na expansão e consequentemente ao acesso a 
esse nível de ensino, resultado da adoção de políticas direcionadas à utilização das Tecnologias de Informação e Comunicação, indispensável no processo de democratização da educação.

\section{REFERÊNCIAS}

AGUIAR, Vilma. Um balanço das políticas do governo Lula para a educação superior:

continuidade e ruptura. Revista de Sociologia e Política, v. 24, n. 57, p. 113-126, mar., 2016.

ANTUNES, Ricardo. O continente do labor. São Paulo: Boitempo, 2011.

ARRUDA, Eucidio Pimenta; ARRUDA, Durcelina Ereni Pimenta. Educação à Distância no Brasil: Políticas Públicas e Democratização do Acesso ao Ensino Superior. Educação em Revista. Belo Horizonte, v.31, n.03, p. 321-338. Julho-Setembro 2015.

BERTOLLETI, Vanessa Alves. A educação superior como estratégia de integração regional: o caso Unila. 200 f. Tese (Doutorado em Educação) - Universidade Estadual de Maringá. Orientador: Dr. Mário Luiz Neves de Azevedo. Maringá, 2017.

BOLSONI, Evandro Paulo (Org.). O Sucesso da EAD Pelo olhar de quem faz. Maringá-PR: Linkania, 2015. p. 97.

BRASIL. Lei de Diretrizes e Bases da Educação Brasileira (LDB) nº 9394, de 1996. Estabelece as diretrizes e bases da educação nacional. Disponível em: http://www.planalto.gov.br/ccivil_03/leis/L9394.htm. Acesso em: 10 dez. 2017.

BRASIL. Resolução no 1, de 11 de março de 2016. Estabelece Diretrizes e Normas Nacionais para a Oferta de Programas e Cursos de Educação Superior na Modalidade a Distância. 2016a. Disponível em http://portal.mec.gov.br/index.php?option=com_docman\&view=download\&alias=35541-rescne-ces-001-14032016-pdf\&category_slug=marco-2016-pdf\&Itemid=30192. Acesso em: 10 dez. 2017.

BRASIL. Inep/Deed. Censo da educação superior 2016 - principais resultados. 2016b. Disponível em:

http://download.inep.gov.br/educacao_superior/censo_superior/documentos/2016/censo_supe rior_tabelas.pdf. Acesso em: 15 jan. 2018.

BRESSER-PEREIRA, Luiz Carlos. A reforma do Estado nos anos 90: lógica e mecanismos de controle. Lua Nova: Revista de cultura e política, n. 45, p. 49-96, 1998.

CALDERÓN, Adolfo Ignacio.; PEDRO, Rodrigo Fornalski; VARGAS, Maria Caroline. Responsabilidade social da Educação Superior: a metamorfose do discurso da UNESCO em foco. Interface - Comunicação, Saúde, Educação. v. 15, n. 39, p. 1185-98, out./dez., 2011.

CARVALHO, Cristina Helena Almeida de. Agenda neoliberal e a política pública para o Ensino Superior nos anos 90. Revista Diálogo Educacional, Curitiba, v. 7, n. 21, p. 83-101, maio/ago., 2007. 
COSTA, Maria Luisa Furlan.; LOZANO, Taissa Vieira. Educação a Distância e Deficiência Visual: Possibilidades e Perspectivas. 2013. Disponível em:

http://proxy.furb.br/ojs/index.php/atosdepesquisa/article/viewFile/3431/2482. Acesso em: 15 jan. 2018.

COSTA, Maria Luisa Furlan.; ZANATTA, Regina Maria (Org.). Educação a Distância no Brasil. Aspectos históricos, políticos e metodológicos. 3. ed. Maringá: Eduem, p. 18, 2014.

DOURADO, Luiz Fernando. Reforma do estado e as políticas para a educação superior no brasil nos anos 90. Educação \& Sociedade, Campinas, v. 23, n. 80, p. 234-252, set., 2002.

DOURADO, Luiz Fernando; OLIVEIRA, João Ferreira de; CATANI, Afrânio Mendes. Transformações recentes e debates atuais no campo da Educação Superior no Brasil. In: Políticas e gestão da Educação Superior. São Paulo: Xamã, p. 17-30, 2003.

FARIA, Elaine Turk. EAD: desafios e propostas emergentes. In: FARIA, E. T. (Org.). Educação presencial e virtual: espaços complementares essenciais na escola e na empresa. Porto Alegre: EDIPUCRS, 2006.

GAJARDO, Marcela. Reformas educativas na América Latina: balanço de uma década. Preal: 2000. Disponível em:

file:///C:/Users/Master/Downloads/reformas_educativas_AL_balance_gajardo_portugues\%20 (1).pdf. Acesso em: 20 nov. 2017.

GENTILI, Pablo. Neoliberalismo e educação: manual do usuário. In: GENTILI, Pablo; SILVA, Tomaz Tadeu (Orgs.). Escola S.A.: quem ganha e quem perde no mercado educacional do neoliberalismo. Brasília: CNTE, p. 9-49, 1996.

GENTILI, Pablo. O discurso da "qualidade" como nova retórica conservadora no campo educacional. In: GENTILI, Pablo.; SILVA, Tomaz Tadeu (Orgs.). Neoliberalismo, qualidade total e educação: visões críticas. 12. ed. Petrópolis, RJ: Vozes, 2007, p. 113-177.

KRAWCZYK; Nora Rut.; VIEIRA, Vera Lúcia. A reforma educacional na América Latina nos anos 90. Uma perspectiva histórico-sociológica. Revista Latinoamericana de Educación Comparada, Ano 01, . n. 01, 2010. Disponível em: http://www.saece.org.ar/relec/revistas/1/art1.pdf. Acesso em: 10 nov. 2017

LARA, Ângela Mara de Barros.; DIAS, Sheila Graziele Acosta Dias. A conferência de Jomtien e suas principais expressões na legislação educacional brasileira da década de 1990: o caso da LDB, do PCN. $1^{\circ}$ Simpósio Nacional de Educação - Cascavel: 2008. Disponível em: http://www.unioeste.br/cursos/cascavel/pedagogia/eventos/2008/5/Artigo\%2003.pdf. Acesso em: 12 fev. 2018.

LITWIN, Edith. Educação a Distância: temas para o debate de uma nova agenda educativa. Porto Alegre, RS, Artmed Editora, p. 1-22, 2001.

LOING, Bernard. Escola e tecnologias: reflexão para uma abordagem racionalizada. Tecnologia Educacional, v. 26, n. 142, p. 40-43, Rio de Janeiro, jul./set., 1998. 
MENDONÇA, Camila Tecla Mortean. O Estado do Conhecimento na Educação Superior a Distância e a Intervenção dos Organismos Internacionais nas Políticas Públicas (2001 a 2014). 137 f. Dissertação (Mestrado em Educação) - Universidade Estadual de Maringá. Orientadora: Prof.Dra. Maria Luisa Furlan Costa. Maringá, 2016.

MORAES, Reginaldo Carmelo Corrêa de. Neoliberalismo - de onde vem, para onde vai? Senac, São Paulo: 2001.

MOREIRA, Jani Alves da Silva.; LARA, Ângela Mara de Barros. Políticas Públicas para a Educação Infantil no Brasil (1990-2001). Maringá: Eduem, 2012.

NISKIER, Arnaldo. Fundamentos da Educação a Distância. In: NISKIER, Arnaldo.

Educação à Distância: a tecnologia da esperança. São Paulo: Edições Loyola, p. 49-75, 1999.

NOMERIANO, Aline Soares.; MOURA, Severina Mártyr Lessa de.; DAVANÇO, Sandra Regina. Expansão do Ensino Superior no Governo Lula da Silva: Prouni, Reuni e Interiorização Das IFES. 2012. Disponível em:

http://educonse.com.br/2012/eixo_13/PDF/11.pdf. Acesso em: 15 nov. 2017.

NUNES, Ivônio Barros. A história da EAD no mundo. In: LITTO, Frederic.; FORMIGA, Marcos (orgs.). Educação a Distância: O estado da Arte. Ed: ABEB, 2009.

OLIVEIRA, Dalila Andrade. Educação básica: gestão do trabalho e da pobreza. PetrópolisRJ: Vozes, 2010.

OLIVEIRA, Silvana Aparecida Guietti de. A Formação de Professores no Ensino Superior a Distância: Limites e Possibilidades de Inserção e Ascensão Profissional. 159 f. Dissertação (Mestrado em Educação) - Universidade Estadual de Maringá. Orientadora: Maria Luisa Furlan Costa. Maringá, 2014.

SADER, Emir. 10 anos de governos pós-neoliberais no Brasil: Lula e Dilma. São Paulo: Boitempo Editorial, 2015.

SHIROMA, Eneida Oto; MORAES, Maria Célia Marcondes de.; EVANGELISTA, Olinda. Política Educacional. Rio de Janeiro: Lamparina, 4a ed., 2011.

\section{Como referenciar este artigo}

RESENDE, Stela Galbardi de; COSTA, Maria Luisa Furlan. Reforma do Estado Brasileiro e a Expansão da Educação a Distância no Brasil (1996-2016). Revista on line de Política e Gestão Educacional, Araraquara, v. 23, n. 1, p. 31-48, jan./abr., 2019. E-ISSN:1519-9029. DOI: 10.22633/rpge.v23i1.11503

Submetido em: 09/12/2018

Revisões requeridas: $15 / 12 / 2018$

Aprovado em: 26/12/2018

Publicado em: 02/01/2019 